\title{
Balkanologie
}

Balkanologie Revue d'études pluridisciplinaires

Vol. VII, n 2 | 2003

Volume VII Numéro 2

\section{Pratiques festives anciennes - nouvelles organisations}

Sandrine Bochew

\section{(2) OpenEdition}

12 Journals

Édition électronique

URL : http://journals.openedition.org/balkanologie/496

DOI : $10.4000 /$ balkanologie.496

ISSN : 1965-0582

Éditeur

Association française d'études sur les Balkans (Afebalk)

Édition imprimée

Date de publication : 1 décembre 2003

Pagination : 73-95

ISSN : 1279-7952

\section{Référence électronique}

Sandrine Bochew, «Pratiques festives anciennes - nouvelles organisations », Balkanologie [En ligne], Vol. VII, n² 2 | 2003, mis en ligne le 19 février 2009, consulté le 17 décembre 2020. URL : http:// journals.openedition.org/balkanologie/496; DOI : https://doi.org/10.4000/balkanologie.496 


\title{
PRATIQUES FESTIVES ANCIENNES - NOUVELLES ORGANISATIONS
}

\author{
Sandrine Bochew*
}

En septembre 1944, l'Armée Rouge pénètre en territoire bulgare. De 1944 à 1946, le gouvernement du Front de la Patrie dirige le pays. Lors des élections de 1946, le Parti ouvrier représenté par G. Dimitrov sort vainqueur. Un gouvernement de coalition avec le Front de la Patrie est formé - il gère le pays jusqu'en 1948 - et une nouvelle Constitution est votée. En 1948, les statuts du Parti ouvrier sont modifiés, il prend le nom de Parti communiste bulgare. Le gouvernement socialiste met en place de nouvelles directives politiques et économiques, principes directeurs de la politique socialiste, qui reposent sur les dogmes marxistes. Les institutions politiques sont mises au service des intérêts économiques de la classe dominante, la classe ouvrière. Les directives, prononcées au cours du $\mathrm{V}^{\mathrm{e}}$ congrès du Parti ouvrier bulgare en 1948 , contribuent à développer l'idéologie du parti dans toutes les sphères de la vie sociale et économique.

Dans le cas des manifestations culturelles, festives et artistiques, toutes les propositions de projets et l'élaboration de programmes culturels émanent du Comité de la culture ${ }^{1}$ qui centralise les décisions. Les directives du ministère sont transmises aux responsables régionaux de la culture qui les font parvenir aux différents présidents des comités locaux. Ces derniers doivent avec les membres du conseil administratif des čitalištes municipales - maisons de culture -

\footnotetext{
- Doctorante en anthropologie sociale - ethnologie, EHESS, Paris.

${ }^{1}$ Sous le régime socialiste, le ministère de la Culture changea régulièrement d'appellation. Les affaires culturelles furent gérées soit par le ministère de I'Éducation soít par celui de la Culture. De 1948 à 1953 , l'activité culturelle dépendait du Comité de la Science, de l'Art et de la Culture. En 1954 fut créé le ministère de la Culture. Jusqu'en 1957, la culture dépendait de ce ministère. À cette date, l'Éducation et la Culture furent regroupées. En 1963, le Comité pour la Culture et l'Art, ayant le statut de ministère, fut créé. Il fut rebaptisé en 1977 en Comité de la Culture qui subsista jusqu'en 1990.
} 
proposer des activités conformes aux exigences politiques nationales. Le budget, affecté à l'élaboration des manifestations culturelles, est important et couvre toutes les formes d'activité culturelle. L'objectif était, à cette époque, de diffuser les directives idéologiques pour que chaque citoyen bulgare puisse "progresser" et tendre vers l'idéal socialiste-communiste. L'héritage culturel devenait l'élément de construction essentiel de la culture socialiste qui s'élabora à partir d'éléments du passé choisis à des fins idéologiques.

Après les changements de 1989, la population s'indigne ouvertement de la propagande et de la manipulation politiques. Les réactions vis-à-vis de cette propagande politique et idéologique sont variées, du rejet à la nostalgie. Parallèlement, la chute des régimes communistes et la mise en place des démocraties permettent à ces sociétés de découvrir et de se réapproprier tout un héritage culturel et traditionnel. À partir de 1990, les décisions concernant la culture sont décentralisées. Un nouveau calendrier de fêtes officielles est instauré. La plupart des célébrations créées durant la période socialiste sont publiquement abandonnées. Le personnel des maisons de culture et les habitants des villes et villages prennent en charge, avec les moyens dont ils disposent, les activités culturelles et festives.

Deux cas de figure sont observables de nos jours dans la plupart des villages bulgares concernant ces animations culturelles et festives. Dans certaines communes, le čitalište gère les calendriers annuels des fêtes et manifestations. Ces calendriers sont définis en fonction des possibilités financières de chaque maison de culture. Dans d'autres communes, quelques familles ou groupes de villageois ont pris l'initiative de célébrer certaines fêtes de saints qui, durant la période socialiste, avaient été interrompues, fêtées dans la sphère privée ou célébrées plus discrètement. Désormais, elles prennent peu à peu de l'importance dans la vie sociale du village. La situation financière des institutions culturelles et la possibilité pour chacun des villageois d'organiser librement et en public certaines manifestations ont contribué à changer certaines habitudes festives.

Mon propos est d'exposer la situation festive actuelle dans un village bulgare $^{2}$ : Boboševo. Dans cette commune, treize fêtes appelées couramment kur-

\footnotetext{
${ }^{2}$ Boboševo est une commune de 1600 habitants qui se trouve sur la route départementale qui mène à Kiustendil, face au massif du Rila. Traversé par la rivière Struma, le village compte sur ses $70 \mathrm{~km}$. (Kepov (Ivan), Minalo i segašo na Boboševo (Passé et présent à Bobochevo), Sofia, 1936, p. 7) de nombreuses chapelles et croix votives. La plus ancienne, estimée du XI ${ }^{e}$ siècle, est dédiée à Saint Todor. Les plus récentes sont par ordre chronologique, les chapelles Saints Dimitri, llia, Michel, la Vierge Marie, Saints Georges, Pierre et Paul. La plus récente, Sainte Petka, a été construite en 1998. Trois croix votives sont situées en différents endroits du village.
} 
bans ${ }^{3}$ sont organisées par des groupes de villageois. Les données ethnographiques ont été recueillies lors de séjours réguliers dans ce village. Le but de cet article est de présenter les personnes qui gèrent et organisent ces célébrations et de déterminer quelles sont les raisons évoquées par les organisateurs pour justifier leur intérêt à préparer ces festivités. De plus, la présence de nouveaux groupes d'organisateurs conduit à s'interroger sur leur rôle au sein de ces organisations et sur les conséquences de leur implication sur l'ensemble de l'activité festive. La présentation de deux fêtes permettra de mettre en évidence les différences observées dans la conception et l'organisation de la fête, ce qui contribuera à présenter deux tendances actuellement observables dans ce village.

\section{LES MAISONS DE CULTURE - ČITALIŠTE : RÔLE DE CETTE INSTITUTION}

Les maisons de culture, appelées couramment en Bulgarie čitalištes, sont des institutions qui jouèrent un rôle important dans le développement de la vie culturelle du pays. Ces établissements se sont développés au XIX ${ }^{\mathrm{e}}$ siècle, lors de la période de la Renaissance bulgare et ont fortement contribué à l'éducation et à la formation des citoyens bulgares, notamment par la diffusion des idées révolutionnaires de l'époque 4 . Ces čitalištes sont organisés en réseau et sont présents dans la plupart des communes (villes et villages). Il en existe plus de 4000 répartis principalement en zone rurale. Ils proposent différentes activités en échange d'une cotisation mensuelle. Les adhérents peuvent ensuite participer aux animations proposées (prêt de livre, groupe de chants ou de danse). Durant l'année, des soirées sont prévues et généralement organisées pour l'ensemble de la population sans distinction.

\section{Fêtes et folklore au service du Parti}

Cette ancienne institution fut pendant la période communiste très active et diversifia son potentiel d'activité (chants, chœur, groupe de danses folklo-

\footnotetext{
3 Le kurban, mot d'origine turque, est généralement exécuté dans un lieu précis (pierre sacrificielle surmontée, en général, d'une croix, église, ...) qui a un rapport étroit avec le destinataire du sacrifice. Les destinataires sont majoritairement des saints : le sacrifice est alors offert le jour même de sa célébration. Quatre types de kurbans sont définis :

- communautaire, don du village au saint avec une participation financière,

- de construction, réalisé pour protéger un nouveau bâtiment,

- personnel, pour implorer ou remercier un saint,

- d'un groupe de personnes, dédié à une divinité, dans des circonstances particulières.

4 La Bulgarie était jusqu'en 1878 sous occupation ottomane.
} 
riques, groupe de théâtre, ...). Certains bâtiments furent reconstruits afin de disposer d'une surface plus grande (salles de spectacles et de répétitions, salle de projection, espace plus important pour la bibliothèque, ...). Des subventions importantes furent prévues et distribuées à ces centres à des fins "d'éducation culturelle". À cette époque, les directives étaient dictées lors du congrès de la culture organisé tous les quatre ans. Elles étaient transmises aux comités régionaux et locaux qui organisaient les manifestations. Les grandes lignes politiques étaient dans leur ensemble suivies (organisation de grands rassemblements et des fêtes les plus importantes5) ; le reste du programme annuel des activités était ensuite décidé lors des réunions du conseil administratif du čitalište, en fonction des besoins de la population et des envies des responsables et membres de la maison de culture.

Les fêtes et rituels étaient le plus souvent organisés par le personnel de ces maisons de culture qui modifiait leur nature pour qu'ils correspondent aux idées politiques de l'époque. Les fêtes religieuses célébrant un Saint, patron d'une corporation, furent transformées selon l'idée socialiste de la société. Elles furent réinvesties par les autorités culturelles d'éléments appartenant à l'idéologie communiste tout en conservant uniquement leur caractère traditionnel. L'objectif était d'imposer le calendrier des festivités socialistes qui, lui, reposait sur des principes économiques et sur l'importance de la classe ouvrière ${ }^{6}$. A Boboševo, un peu avant les années 1970, les dirigeants décidèrent d'adapter selon les critères idéologiques la fête de St Trifon, dite fête des vi-

\footnotetext{
5 J'ai consulté les historiques et les inventaires des fonds d'archives concernant les différents ministères de la culture de la période communiste. Jusque dans les années 1970, il n'y a eu, à ma connaissance, aucun document archivé concernant les rituels et festivitès. Dès les années 1970, il est possible de trouver certains documents traitant des fētes officiellement célébrées en République populaire bulgare. Citons par exemple, la typologie des fêtes qui avait été définie lors d'une commission composée d'ethnographes et folkloristes en mai 1978. Dans le cas du calendrier des fêtes et des manifestations socialistes, les festivités étaient divisées, selon les ethnographes de cette époque, en six groupes :

- rituels de la vie familiale,

- rituels de la vie sociale et des collectivités politiques,

- fêtes des travailleurs,

- jours fériés du cycle calendaire et leurs rituels,

- rituels des traditions militaires - patriotiques,

- jours fériés politiques de la tradition révolutionnaire.

De même, en 1981, un programme annuel de fêtes fut élaboré pour instaurer progressivement un calendrier de type socialiste. Il est indiqué à quelles fêtes passées correspondent ces nouvelles célébrations. Les objectifs et les raisons de la célébration sont mentionnés dans ce programme. Par exemple, le 3 mars date à laquelle fut signé le traité de San Stefano en 1878 -, fête " nationale et socio-politique ", symbolise le jour de la libération de la Bulgarie par le peuple russe de " l'esclavage ottoman ". L'action patriotique et éducative et l'expression d'une amitié séculaire entre les peuples russe et bulgare sont les raisons évoquées pour justifier cette célébration.

${ }^{6}$ Un ancien responsable de la culture durant les années 1970-1980 raconte : " nous faisions et organisions certaines fêtes et coutumes religieuses mais on ne disait pas fêtes mais rites, traditions en introduisant dans ces fêtes des éléments nouveaux et en rejetant les détails authentiques dans le but de changer la fête, pour dénigrer le rôle de la religion " (entretien, avril 2001).
} 
gnerons. Cette fête au caractère religieux devint la fête la plus importante de la corporation des vignerons et l'une des plus importantes de Boboševo, village avant tout agricole. Beaucoup de personnes se déplaçaient pour y assister. Le chœur des femmes prenait part à la fête. Le rituel spécifique de la fête, la taille de la vigne, était complété par des célébrations sur la place centrale ou dans la salle des spectacles. Cette fête, symbolisant le début du travail aux champs, était enrichie d'éléments valorisant la conception socialiste du travail. Lors de la fête des éleveurs (fête de St Georges), aucun rituel n'était prévu. On organisait un repas commun dans les grandes coopératives. Les chefs des TKZS7 récompensaient les meilleurs éleveurs, les plus méritants, avec une prime.

La coutume était, de même, présentée au public sous la forme de saynètes (à l'occasion, par exemple de la fête des vignerons). Le but de ces pièces de théâtre était pédagogique et culturel ; le public avait la possibilité " de découvrir et d'apprendre " ce qu'on lui présentait comme la culture traditionnelle. La tradition était interprétée pour servir les principes politiques, symbolisant un passé révolu. Des festivals de danses et de musiques folkloriques étaient également organisés et soumis aux directives idéologiques. Le folklore dansé et chanté était mis en scène pour être présenté ensuite comme un spectacle.

Le calendrier de cette époque était fécond en événements et en commémorations. Toutes les dates et périodes appartenant à l'histoire socialiste ou considérées comme "progressives" pour l'histoire bulgare étaient célébrées en étant investies d'un symbolisme propre aux idées communistes. Par exemple, l'écriture cyrillique et la culture bulgare étaient fêtées le 24 mai ; auparavant, cette fête était dédiée aux Sts Cyrille et Méthode. Les dates historiques pour la république populaire bulgare, tel le 9 septembre $^{8}$, étaient fêtées en grande pompe. Certaines personnalités, ayant joué un rôle important dans l'histoire du pays et dans l'instauration du socialisme en Bulgarie, ètaient honorées à certaines dates (Vasil Levski, Christo Botev, Georgi Dimitrov, ...) ou lors de dates anniversaires.

\section{Et après 1989 ?}

Après 1989 , toutes ces institutions culturelles sont devenues totalement libres de leurs choix. Un calendrier festif annuel fut élaboré mais peu connu par

\footnotetext{
7 Les Trudovo Kooperativno Zemedelsko Stopanstvo sont des fermes coopératives. Un des objectifs du Parti était de collectiviser les moyens de production. Dans le cas de l'agriculture, les terres ont été regroupées et collectivisées. Dès 1956, ces fermes coopératives permettaient d'aboutir à cette forme de collectivisation. Plus tard, en 1959, les TKZS sont regroupés avec les fermes d'État. En 1970, le Parti décide la création des APK (Agrarno Promišleno Kompleks, complexes agro-industriels) qui sont une nouvelle concentration des fermes coopératives et d'État.
}

8 Cette date symbolise l'instauration progressive du régime communiste en Bulgarie. En effet, l'Armée rouge, après la déclaration de guerre de l'URSS à la Bulgarie, le 5 septembre 1944, franchit les frontières bulgares et envahit la capitale. Une armistice provisoire fut signée le 9 septembre. 
les responsables des maisons de culture, il est actuellement peu suivi. Sans soutien logistique et livrés à eux-mêmes, les fonctionnaires de ces structures locales sont confrontés actuellement à une situation financière difficile qui les empêche de proposer un programme riche d'activités et de festivités. En 1996, une loi est votée sur la réforme du statut des maisons de culture; elle stipule que ces établissements, institutions culturelles et éducatives, peuvent, si les responsables le désirent, recouvrer leur autonomie juridique et leur titre à la propriété foncière et immobilière. Ce nouveau statut leur permet de rechercher des financements privés, sous la forme de sponsors ou de mécénat, d'exercer une activité commerciale, notamment la location de salles de l'établissement, de jouir de la gratuité de leurs locaux et de n'être plus imposées sur les activités de base. Or, la mise en pratique de cette loi se révèle délicate. Il est difficile pour ces structures de s'autofinancer et de ne plus dépendre des financements municipaux. Trouver des sponsors relève d'une démarche ardue et se lancer dans une activité commerciale reste aléatoire.

Dans le cas de Boboševo, cette loi de 1996 est un problème majeur pour les responsables du čitalište. La maison de culture date de 1870 et représente encore pour les villageois un lieu actif de culture. Mais la situation actuelle ne permet pas de répondre aux nombreuses attentes de la population. Les responsables de l'activité culturelle, qui étaient déjà en poste avant 1989 , peuvent donc constater la différence au niveau des financements. D'après un des membres du conseil administratif de la maison de culture, il ne " manquait pas de financements qui étaient suffisants. On dépensait sans regarder et il est possible qu'il y ait eu du gaspillage "9. D'importantes subventions contribuaient à l'achat de nouveaux livres et de nouvelles installations et à proposer au public des spectacles récents. Actuellement, le constat est affligeant : les activités proposées sont moins nombreuses car le budget alloué suffit seulement à payer les salaires des employés qui sont au nombre de trois (une femme de ménage, la bibliothécaire et la personne responsable des activités culturelles). Néanmoins, un programme annuel de manifestations et de soirées est prévu et décidé en conseil administratif ${ }^{10}$ qui se réunit chaque mois ou trimestre. L'année culturelle commence en octobre. Les principales manifestations proposées sont liées soit à l'histoire du pays (le 3 mars, fête nationale, le 24 mai pour la fête de la culture et de la science, ...) soit aux personnes ayant contribué au renouveau national ou local (l'historien local et le premier instituteur ayant contribué au XIX ${ }^{\mathrm{e}}$ siècle au développement de l'éducation laïque, ...). De même, les animations sont réalisées avant tout sur la base du bénévolat. La responsable de la culture s'occupe de différents groupes de bénévoles :

9 Entretien, novembre 2000.

10 Tous les trois ans, une assemblée générale, composée des membres de la maison de culture (une centaine d'adhérents), est organisée pour élire les membres du conseil (neuf). 
- un groupe d'enfants pour des chants et danses folkloriques et pour des soirées sketchs,

- un groupe composé d'anciens enseignants principalement, pour des soirées littéraires,

- le chœur " la source de la Struma " et son registre de chants.

Depuis 1996, ce čitalište est juridiquement indépendant mais, faute de moyens financiers, la mairie assure une participation financière et humaine occasionnelle. Le comptable de la mairie gère les comptes de la maison de culture. Pour ces institutions, qu'elles soient indépendantes ou encore sous la tutelle des municipalités, les subventions demeurent hypothétiques ou limitées. L'avenir de ces établissements qui, par le passé, avaient contribué au développement de la culture est incertain, de l'aveu même des membres de ce čitalište ${ }^{11}$. Malgré leur bonne volonté, il est difficile de proposer localement un programme d'activités correspondant à l'actualité culturelle et aux demandes de la population. Aucune décision importante n'a été prise et les chances de développement de ce secteur d'activités sont faibles. De plus, pour ce village et comme pour la plupart des localités bulgares, toute l'activité culturelle émanait de la maison de culture qui faisait office de théâtre, de cinéma, de bibliothèque, de salle de concerts. Il ne reste alors pour les villageois que cette institution pour pouvoir emprunter des livres (souvent anciens car le fonds n'a pas été enrichi des dernières nouveautés littéraires), se rendre à un spectacle (déjà présenté de nombreuses fois) et participer à la vie culturelle villageoise ${ }^{12}$.

Les activités culturelles de la maison de culture de Boboševo étant moins nombreuses, les occasions pour les villageois de se retrouver sont plus rares. De ce fait, les fêtes d'un type plus traditionnel - les kurbans organisés en l'honneur d'un saint - prennent plus d'importance dans la vie sociale locale. Ces festivités, célébrées tout au long de l'année, sont sous la responsabilité de groupes de villageois. Ces célébrations religieuses sont prétexte également à des moments d'échanges et de partages pour les participants : " aux kurbans, on échange les expériences "13. La maison de culture ne prend nullement part à l'organisation de ces kurbans qui appartiennent avant tout à l'espace public non institutionnalisé.

\footnotetext{
${ }^{11}$ Un des anciens responsables de la maison de culture explique cette situation en la comparant à celle du passé : « la différence est comme l'Etat ne donne pas d'argent à la culture, la culture ne se fait pas sans argent. On ne peut pas pour les maisons de culture faire un programme comme auparavant avec de grandes représentations car cela ne suffirait pas à payer toutes les dépenses par la seule vente des billets... Il est nécessaire d'avoir beaucoup de choses. Avant, les coopératives, les TKZC et l'usine de fourrage donnaient de l'argent. Maintenant, il n'y a rien " (entretien, avril 2001).

${ }^{12}$ Il est à noter que cette situation de crise existait déjà avant 1989 et n'en fut que plus accentuée par les changements. Durant plus de quarante ans, les volontés culturelles de toutes les personnes impliquées dans une activité artistique étaient définies par le politique. Il fut nécessaire, pour s'adapter aux changements, de redéfinir ces choix qui dépendent maintenant de l'économie de marché.
}

13 Entretien, décembre 2000. 


\section{LES FÊTES - LES KURBANS}

Pendant la période communiste (plus précisément pendant les années 1980), neuf fêtes étaient organisées plus modestement et plus discrètement à Boboševo. Peu à peu, après les changements de 1989 , des villageois ont décidé de célébrer de nouveau des kurbans qui avaient été plus ou moins oubliés. Jusqu'en 1998, douze fêtes étaient préparées durant l'année. En 1998, certains villageois ont décidé pour la fête de Saint Trifon (saint patron des vignerons) de proposer un kurban.

Actuellement, à chaque emplacement du site dédié à un saint (croix votives et chapelles), est régulièrement préparé un kurban. L'organisation de ces fêtes dépend de la situation géographique des lieux votifs qui sont localisés dans les différents quartiers - ou mahala - du village. Ces kurbans sont organisés dans trois des six quartiers que compte Boboševo.

Dans le premier, situé à l'entrée du village, une seule fête est célébrée : Saint Ilia. Dans le deuxième, situé sur la route qui mène à Kiustendil, quatre kurbans sont réalisés. L'un d'eux, Sainte Petka, est sous la responsabilité d'un groupe récemment constitué. Les trois autres (Saint Todor, Saint Spas et Saint Nicolas) sont organisés par un groupe qui a son propre responsable, son cuisinier et ses aides.

Dans le dernier quartier, situé à l'extrême sud du village, ont lieu huit fêtes (Saint Trifon, Saint Georges, " Umni Petăk "14, la Trinité, Saints Pierre et Paul, la Vierge Marie, Saint Dimitri et Saint Michel). Pour la célébration de la Saint Trifon, le groupe créé depuis 1998 est aidé d'autres responsables du quartier. Le cas de Saint Georges est particulier car les données ont évolué durant l'année 2001. Pour les six autres fêtes, chaque responsable du kurban est aidé d'autres organisateurs du quartier. Le même cuisinier s'occupe de préparer chaque kurban et lui-même est organisateur d'une des fêtes.

\section{Le kurban à Boboševo}

Quelques jours avant la fête, le responsable et ses aides circulent en carriole dans les rues pour demander aux villageois de participer à la réalisation du kurban en offrant différents ingrédients (oignons, poivrons, tomates, riz, huile, farine, ....). Le responsable stocke ensuite ces aliments généralement chez lui jusqu'à la veille de la fête. La veille, les hommes se regroupent pour égorger des bêtes supplémentaires afin de disposer de suffisamment de viande. Ces animaux ne sont pas choisis selon des critères particuliers pour le rituel. Ils sont achetés avec l'argent recueilli lors de la fête précédente. Le travail d'abattage est considéré comme difficile et défini comme une tâche masculine. En effet, il faut 
non seulement savoir égorger correctement la brebis pour que la viande soit comestible mais être habile pour le dépeçage qui est une tâche longue et harassante. Toute la préparation se déroule simplement et sans rituel particulier. Les bêtes dépecées sont ensuite nettoyées et conservées jusqu'au lendemain. La viande sera préparée sur le lieu même de la fête. D'autres personnes se regroupent pour commencer à émincer les légumes (tomates, poivrons et oignons) qui sont entreposés au frais dans de grands seaux jusqu'au lendemain. Ce travail est confié généralement aux femmes. Pour certaines fêtes de moindre importance, la préparation des légumes s'effectue le jour-même.

Le jour de la fête, tôt le matin, le responsable et ses aides se rendent au lieu votif (la croix ou la chapelle) pour immoler l'animal exécuté en l'honneur du saint, désigné comme l'offrande et communément appelé kurban. Ce sacrifice communautaire symbolise le don d'un animal offert par l'ensemble du village au saint qui protégera ensuite la communauté. En général, lors de la fête en l'honneur d'un saint, l'animal offert est un mâle, pour une sainte, une femelle. Cette bête doit être la plus belle et normalement de couleur blanche. L'animal n'est pas au préalable bénit ; aucune prière n'est prononcée car le pope n'est généralement pas présent pour le rituel. Un peu de sang de l'animal est versé sur la base de la croix ou sur les murs de la chapelle. Cet acte a pour valeur de protéger le lieu consacré au saint célébré ce jour-là. L'animal sera ensuite préparé pour être consommé sous forme d'une soupe, sauf dans le cas de la Saint Georges, où l'agneau immolé est rôti. Il est à mentionner que le terme de kurban désigne également plus largement dans l'esprit des villageois la fête et le repas.

Les organisateurs se retrouvent tous au lieu votif pour préparer le repas qui sera servi soit en début d'après-midi pour les fêtes d'hiver (les journées étant plus courtes) soit en fin d'après-midi pour les fêtes estivales (les villageois sont généralement encore dans les champs ou sur leur lieu de travail). Tous les organisateurs n'ont pas l'habitude de préparer le kurban; seuls deux organisateurs sont reconnus dans le village comme étant les meilleurs cuisiniers et les plus aptes à le faire. Ils sont alors régulièrement sollicités pour préparer ce repas. Si la soupe est bonne, le cuisinier et les responsables y trouveront une reconnaissance auprès des villageois.

Dès neuf heures du matin, dans l'église principale consacrée à la Vierge Marie, une messe est prononcée par le pope qui se rendra ensuite au lieu de la fête pour bénir le repas et les villageois présents. Parallèlement, la responsable de la culture au čitalište $e^{15}$ annonce à la radio locale l'heure à laquelle la fête débutera. Les villageois sont invités à s'y rendre. Cette annonce radio est avant tout une note d'information à l'attention des villageois.

${ }^{15}$ Cette personne réalise des programmes radiophoniques émis à Boboševo dans le cadre des activités de la maison de culture. 
Un peu avant l'heure prévue, les villageois, chargés de quelques bouteilles de vin et d'eau-de-vie, de pain, de conserves et de charcuterie, se rendent à pied, en voiture ou en carriole au lieu même de la fête. Les responsables les accueillent. Avant de s'installer à même le sol, chaque personne dépose quelques offrandes au saint (généralement des chaussettes, des serviettes, du savon, ...) et brûle un ou plusieurs cierges. Il est de coutume lorsqu'on pénètre dans une église orthodoxe de brûler au moins un cierge. De nombreuses femmes déposent également une pitka. Ce pain est préparé en l'honneur et pour la santé d'une des personnes de la famille ayant pour prénom celui du saint célébré ce jour-là. Ces pains sont bénits par le pope ; ils sont ensuite partagés. Le pope se rend devant les grosses marmites contenant le kurban. Il bénit le repas et ensuite l'assemblée. La distribution de la soupe, le kurban, commence. Les responsables de la fête se déplacent avec des seaux pour servir chaque groupe de villageois. Parallèlement, les personnes qui le désirent, peuvent réserver une part payante de soupe bénite pour en ramener un peu chez soi. En effet, le kurban, une fois bénit, posséderait des vertus protectrices et serait salutaire pour la santé. Ensuite, une personne du groupe des organisateurs circule avec un plateau pour demander à chacun des villageois une contribution financière qui permettra d'entretenir le lieu votif et de réaliser le prochain kurban. Enfin, les différents dons offerts au saint sont proposés aux enchères. Les sommes d'argent recueillies contribueront également à financer la fête suivante. Progressivement, les villageois quittent les lieux pour rentrer chez eux.

\section{ORGANISATION FESTIVE ET RELATIONS SOCIALES}

Durant la période communiste, l'ensemble de l'activité culturelle était géré par le čitalište. Les kurbans étaient peu célébrés. Toute la vie culturelle et sociale s'organisait autour des manifestations de la maison de culture. La plupart des organisateurs sont bien conscients que si durant cette période, les kurbans étaient moins célébrés, c'est qu'ils ne correspondaient pas aux préceptes de l'époque. Les traditions et le folklore, qui étaient instrumentalisés à des fins idéologiques, servaient de référents culturels pour l'édification et l'élaboration de la culture socialiste. La plupart des fêtes publiques étaient contrôlées et seules les fêtes correspondant plutôt à l'idéologie socialiste pouvaient être célébrées sur la place publique. Actuellement, les villageois ont la possibilité de prendre en charge ces festivités plus ou moins oubliées. Parallèlement, la maison de culture n'est plus en mesure de garantir financièrement sa mission d'éducation et d'offre culturelles. De même, le rôle de lien social qui s'établissait entre les habitants au cours des diverses rencontres culturelles n'est plus totalement assuré. L'activité sociale et le sentiment d'appartenance à un groupe se 
retrouvent lors de la célébration de ces fêtes qui donnent la possibilité aux villageois de partager des moments de convivialité. Au cours de mes entretiens réguliers auprès des organisateurs de ces festivités, j'ai pu déterminer et mieux comprendre ce qui les motivaient à célébrer ces kurbans.

\section{Tradition - religion - identité}

Lors de mes premiers contacts, je supposais que l'organisation et la célébration de ces kurbans étaient l'expression d'un sentiment d'appartenance à un groupe enclin à préserver et maintenir une tradition festive. Mon objectif était de déterminer quels étaient les arguments présentés par le groupe de villageois (organisateurs et participants) pour justifier leur intérêt pour ces fêtes. Lors des entretiens que j'ai menés auprès des organisateurs et des villageois se rendant à ces fêtes, les villageois invoquaient principalement l'intérêt pour cette vieille tradition festive transmise de génération en génération : " cela reste du temps ancien qui nous précède. Les vieux ont fait et nous continuons la tradition et on doit la transmettre ${ }^{16}$. L'organisation de ces fêtes dépendait non seulement de l'attrait pour cette tradition mais aussi de la volonté de les maintenir : " parce que ce sont des vieilles traditions qui datent de nos grands-pères... Il faut continuer la tradition quel que soit le régime. C'est une des plus belles choses qui restent de nos ancêtres et il faut et on doit continuer ${ }^{17}$. Or, à l'analyse, il est apparu que ce désir de préserver et de transmettre cette tradition ne semblait pas être la seule raison présidant à la célébration de ces rituels.

Transmettre une tradition, perpétuer un rituel permet au groupe de s'identifier à une histoire et de se constituer une identité locale. La réalisation et l'organisation de ces festivités apparaissaient donc comme un facteur d'identité locale ou nationale. Explicitement, les organisateurs et les participants justifiaient leur intérêt pour ces rituels en se référant à leur identité nationale : " la tradition est une grande chose pas seulement pour moi en Bulgarie mais pour beaucoup de gens. Les traditions sont conservées seulement par le fait qu'on ne veut pas perdre l'identité de la Bulgarie. (...) Je suis bulgare et je veux que les traditions bulgares continuent à exister en Bulgarie ${ }^{18}$. Permettre à ces traditions d'être transmises aux générations futures s'expliquait par la nécessité de disposer de cette identité bulgare pour pouvoir exister : " c'est en nous, c'est national, sans cela on n'est pas bulgare, on n'est pas une nation. (...) Sans tradition, on perd ses racines. (...) La tradition, c'est notre côté bulgare "19. Or

\footnotetext{
${ }^{16}$ Entretien, novembre 2000.

17 Entretien, novembre 1999.

${ }^{18}$ Entretien, avril 1996.

19 Ibid.
} 
lorsqu'ils se référaient au concept d'identité bulgare, la plupart des organisateurs étayaient leur réflexion en évoquant l'histoire nationale : " c'est une tradition. Si on ne fête pas ces fêtes purement bulgares, la Bulgarie serait perdue. Pendant les 500 années de joug turc, imagine si ces fêtes n'avaient pas existé, comment les Bulgares auraient pu exister. (...) La tradition garde le peuple, garde ce qui est bulgare ${ }^{20}$. La référence à l'histoire contribuait à légitimer leur intérêt pour la préservation de ces festivités considérées comme la tradition locale. Ce goût pour la tradition et sa justification par le rappel de l'histoire permet donc aux organisateurs et aux participants d'affirmer également leur identité bulgare au sein du village.

\section{8 : l'année des changements}

En 1998, il y eut des changements dans l'organisation des fêtes. Certains villageois décidèrent pour la fête de Saint Trifon (saint patron des vignerons) d'organiser un kurban. De plus, quelques personnes prirent l'initiative de construire une chapelle, là où se trouvait auparavant une simple croix votive. D'autres changements furent constatés. Les motivations des villageois qui se sont engagés dans la restauration de bâtiments religieux ou la célébration de nouvelles fêtes sont-elles les mêmes qu'avant 1998 ? Ces évolutions sont-elles mues par le même intérêt, celui du maintien de leur tradition ? La présentation des transformations intervenues dans l'organisation des festivités, ces dernières années, nous permettra ensuite d'analyser les différents points de vue des organisateurs.

Dès 1998, un comité d'initiative est créé. L'idée principale de cette organisation est de protéger le patrimoine local. L'initiateur de ce groupe est un villageois de Boboševo. Son idée est d'aider financièrement et matériellement à la restauration des chapelles du village et plus particulièrement à celle de Saint Georges $^{21}$. Les actuels organisateurs de la fête de Sainte Petka font partie de cette association. Au cours de l'année 1998, à l'emplacement de la croix votive dédiée à Sainte Petka, ce groupe de personnes décida de construire une chapelle.

Les différents membres de ce comité ont parcouru le village pour trouver de l'argent. Un des membres raconte comment les villageois ont participé financièrement à la construction :

on a ramassé l'argent des gens, cela représentait " des sacrifices volontaires », cela venait du cœur. Qui veut donne. Il y a des gens qui ont donné ce qu'ils pouvaient en fonction de leurs moyens. (...) Et la chanteuse Jordanka, célèbre chanteuse de folklore dans toute la Bulgarie [elle est originaire de Blagoevgrad et mariée à un

${ }^{20}$ Ibid.

${ }^{21}$ Le grand-père de cet initiateur aurait aidé à la restauration de la chapelle St Georges, il y a plus de 70 ans. 
villageois de Boboševo] a fait un concert à Boboševo et avec les recettes qu'elle a reçues, elle les a données pour la construction $\left(360\right.$ leva $\left.{ }^{22}\right)$. Tous ont donné et avec cet argent on a acheté des tuiles pour la toiture et pour l'abri. ${ }^{23}$

La mairie a participé à cette construction en offrant quelques matériaux et en proposant l'aide de certains des ouvriers municipaux. Toutes les personnes qui par leur geste ont contribué à la construction de la chapelle, estiment que cette participation est liée au respect d'une tradition et de la religion orthodoxe. Le don est également considéré par les villageois comme une contribution personnelle à l'événement.

Pour construire cette chapelle, il était nécessaire d'avoir l'autorisation du Saint Sinot (patriarcat de Bulgarie) et non de la mairie car les terrains appartiennent à l'Église orthodoxe bulgare en raison de la présence d'une croix votive. L'accord ne dépendait que du respect par l'architecte des normes de la tradition orthodoxe (emplacement du chœur vers l'est).

La construction de la chapelle commença le $1^{\mathrm{er}}$ avril 1998. L'objectif était de la terminer le 14 octobre, jour de la fête. Avec l'aide du personnel de mairie, la construction fut vite réalisée. Les fresques à l'intérieur de la chapelle ont été peintes bénévolement. En effet, un des responsables connaît de longue date un des enseignants de l'Académie des Beaux-Arts. Cet ami lui proposa de venir gratuitement avec des étudiants pour réaliser les fresques. Le gîte et le couvert était leur seule rémunération. Cet enseignant apporta également le matériel et la peinture nécessaires. Il réalisa ce travail principalement par amitié. La croix qui surmonte le clocheton de la chapelle a été offerte par certains villageois. La chapelle Ste Petka fut terminée pour le 14 octobre 1998 et inaugurée à l'occasion de la fête.

Au cours de l'année 2001, certains des membres du groupe responsable de la Ste Petka ont décidé de restaurer la chapelle St Georges. Cette chapelle n'est pas répertoriée comme un monument du ministère de la Culture, ce qui rend possible la réalisation de certains travaux sans autorisation particulière. Ces travaux devaient être terminés pour la fête de St Georges et ont été réalisés à temps. Les personnes qui ont participé à la construction ont été félicitées et la fête fut un succès. Elles ont prévu pour l'année suivante de réaliser d'autres travaux (construction d'un four et d'un auvent) pour que le kurban en l'honneur du Saint soit une réussite complète ; ce qui fut fait pour la fête du 6 mai 2002.

Il est prévu qu'à l'emplacement de la croix votive de Ste Trinité, une chapelle soit construite. Le groupe organisateur de cette fête n'est pas impliqué dans ce projet de construction. Néanmoins, il en connaît l'existence et l'approuve. Une des personnes responsables de la fête de Ste Petka, membre du

${ }^{22}$ Actuellement, un euro vaut environ 2 leva ; 360 leva nouveaux correspondent donc à environ 180 euros.

23 Entretien, avril 2000. 
groupe de restaurations des chapelles, a été désignée comme responsable du projet et de sa mise en oeuvre. Cette construction est financée par un villageois qui vit en Italie. Actuellement, le projet est toujours en attente.

Dans le cas des restaurations des chapelles ou de la construction de lieux votifs, l'intérêt manifesté par ces différents groupes est justifié par le profond respect qu'ils entretiennent à l'égard de la religion orthodoxe. Un des membres de l'organisation de la fête de Ste Petka explique les raisons qui les ont motivés à construire cette chapelle : " on a créé une association et avec enthousiasme on a commencé à construire Sainte Petka. A vrai dire, on est tous contents de ce qu'on a fait. Nous cinq, on a fait la promesse, ce n'était qu'une croix votive et on en a fait une chapelle pour la Sainte. (...) J'ai voulu le faire pour Sainte Petka. J'ai fait cette promesse ${ }^{24}$. Or les organisateurs justifient leur intérêt pour la religion et leur respect du saint en se référant à l'histoire de ces fêtes et aux souvenirs qu'ils en avaient : " je peux te montrer des photos lorsque j'étais enfant, il y avait une foule que tu ne peux pas imaginer. Dix à vingt fois plus. Il y avait au moins sept gros chaudrons " 25 . Parallèlement, la raison de leur participation à la construction et à la restauration du patrimoine religieux se justifie par l'histoire locale. La plupart de ces organisateurs font référence à l'historien local, Kepov, qui, dans les années trente, publia une monographie du village. Dans cette étude, il présente et décrit les nombreuses chapelles construites et répertoriées sur le territoire de Boboševo. Cette référence crédibilise à leurs yeux leur intérêt à construire de nouveaux lieux votifs et à préserver le patrimoine local : " par ici, on a beaucoup construit. (...) C'est peut-être le deuxième village qui a le plus de chapelles et d'églises en Bulgarie $n^{26}$. Le respect des coutumes traditionnelles et de la religion orthodoxe s'explique par l'importance du patrimoine historique et religieux local. La référence à l'histoire et à l'historien local, Kepov, apporte cette plus value et justifie leur intérêt initial :

l'histoire ne nous dit pas à partir de quand les traditions ont commencé. Le fait qu'il y ait des chapelles depuis des siècles nous montre que ces traditions ont commencé avec le christianisme. Les gens ont besoin de cette force pour se protéger. Après, cela est transmis de génération en génération. (...) C'est une vieille tradition d'honorer les saints pour avoir une aide pour la vie privée ou la santé. Mais avant tout, les gens faisaient cela pour la santé. Et même pour ceux qui étaient agriculteurs ou éleveurs, ils avaient un saint patron. (...) Chaque métier a son saint patron et c'est pour cela que les gens construisaient les chapelles et églises. ${ }^{27}$

\footnotetext{
${ }^{24}$ Entretiens, avril et juin 2000.

25 Entretien, mai 2000.

${ }^{26}$ Ibid.

${ }^{27}$ Entretien, novembre 2000.
} 
L'implication dans la restauration et la construction de lieux votifs s'analyse donc non seulement comme une marque d'intérêt pour une certaine forme de tradition et de respect à l'égard d'un saint, mais aussi comme la nécessité pour ces organisateurs de s'impliquer dans l'histoire de leur localité : " ma génération future pourra dire : mon grand-père là-bas a fait quelque chose $n^{28}$.

Au cours de l'année 1999, un groupe constitué récemment décida de célébrer St Trifon en sacrifiant un animal en l'honneur de ce St patron des vignerons. Pour cette fête, aucun kurban n'est habituellement organisé. Le responsable du groupe a voulu innover. Il explique les raisons de ce choix : "parce que c'est le jour des vignerons et moi je suis producteur de vin et nous nous sommes rassemblés dans une auberge et les autres ont dit : "il y a tellement de lieux votifs à Boboševo, pourquoi ne pas en faire un pour Trifon ?". Et j'ai dit d'accord. Et j'ai fait une promesse de donner chaque année un bouc pour cette fête, c'est un don ${ }^{29}$. D'autres villageois se sont associés à son idée et depuis 1999, ils organisent ce kurban.

Si le vœu et la promesse effectués devant un groupe d'amis ont motivé cette personne pour réaliser cette nouvelle fête religieuse, la référence à une littérature historique et religieuse demeure également essentielle. Les membres de cette organisation font référence non seulement à la tradition du travail des vignes, évoquée dans la monographie du village : " le jour de Trifon est le patron des vignerons, c'est une fête traditionnelle. D'après Kepov, le travail des vignes est important car cela donnait beaucoup de pain ${ }^{30}$; mais aussi aux attributs symboliques de St Trifon : " j'ai lu que St Trifon est protecteur des hommes ". Dans ce cas précis, l'utilisation de sources écrites leur permet de conforter et de valoriser leurs choix.

La fête, kurban, correspond pour l'ensemble des organisateurs à une tradition à respecter et à transmettre : " c'est héréditaire " $3^{11}$. Participer et s'impliquer dans l'organisation de ces festivités se justifie en invoquant l'histoire locale et la tradition qui peuvent être analysés comme des marqueurs identitaires ${ }^{32}$. Les récents changements observés depuis 1998 permettent de confirmer ces premières constatations. Toutefois, le respect pour la religion et

\footnotetext{
${ }^{28}$ Entretien, octobre 1999.

29 Entretien, mai 2001.

$3^{\circ}$ Cette personne, ayant travaillé au sein de l'entreprise productrice du vin et comme spécialiste agronome dans le TKZS de Boboševo, sous-entend par le terme de "pain" que l'activité vinicole était la source principale de rendement et de travail au sein du village. Entretien, novembre 2000.
}

${ }^{31}$ Entretien, avril 2001.

32 J'entends par marqueur identitaire la référence au concept de marqueur de l'identité culturelle (l'ensemble des éléments tels la langue, le costume, le comportement alimentaire, les loisirs, ...). Tous ces éléments constituent pour le groupe le moyen de se "démarquer" par rapport aux autres et d'affirmer son appartenance à un groupe local. 
pour les saints célébrés a été plus régulièrement cité lors de nos entretiens. L'aspect religieux est à prendre en compte car il est pour la plupart des organisateurs un facteur essentiel dans la réalisation de la fête. Pourtant, cet élément ne modifie guère nos premières constatations car l'identité culturelle locale et l'identité religieuse se complètent. Or, des questions restent en suspens : quelle est la démarche habituelle que doit effectuer le villageois pour devenir organisateur ? La présence récente de ces nouvelles personnes au sein de l'organisation de ces festivités a t-elle généré de nouveaux rapports entre les différents organisateurs?

\section{Le conseil des organisateurs et le choix du responsable}

Aux dires de l'ensemble des organisateurs, le choix d'un responsable est décidé en conseil par quartier. Ce conseil est composé des principaux organisateurs des kurbans du mahala. Généralement, pour chacune des fêtes, un responsable est nommé pour gérer les comptes et planifier les achats et les tâches. Il est aidé et conseillé par d'autres villageois, souvent eux-mêmes des organisateurs d'autres kurbans. Le groupe, constitué du responsable et de ses aides, est toujours composé de trois ou cinq personnes, nombre impair - le nombre impair ayant pour symbolique la vie et la santé. Or, dans le cas où le responsable ne pourrait pas préparer le kurban (maladie ou déplacement), il choisira, parmi les personnes qui l'aident régulièrement, son remplaçant. En cas d'abandon, il proposera une personne pour lui succéder. En cas de décès, c'est généralement la personne qui se sera la plus investie et impliquée dans la préparation de la fête qui sera choisie par l'ensemble du conseil. Pour les villageois de Boboševo, un organisateur doit posséder les qualités suivantes :

- bien faire l'ensemble du travail,

- avoir de l'autorité et avoir la confiance des autres villageois,

- être majeur et donc responsable devant la loi.

Dans l'absolu, être organisateur, c'est faire preuve de volonté pour pouvoir être choisi par le groupe : « c'est la personne qui montre sa volonté. Si tu n'as pas de volonté, personne ne pourra te choisir "33. Le nouvel organisateur accepte alors toutes les responsabilités liées à la réalisation de la fête. Dans un premier temps, il s'engage à réaliser, chaque année, le kurban quelle que soit la situation : " l'organisateur prend toutes les responsabilités et s'il y a l'argent ou pas, il doit trouver l'animal „34. Dans un deuxième temps, par cet engagement, la personne participe au maintien d'une tradition qui sans son investissement personnel disparaîtrait : “ je ne fais rien pour moi, mais si je n'étais pas là, il n'y 
en aurait pas. Il n'y a personne dans le quartier pour prendre la responsabilité et sinon cela serait oublié $" 35$. Or, en participant au maintien de ces fêtes, les organisateurs se positionnent socialement et acquièrent une certaine notoriété au sein de leur village. La présentation de deux fêtes au travers des raisons et des choix évoqués par l'organisateur responsable permettra de mettre en évidence deux types de démarche et de représentation du rôle de l'organisateur.

\section{Les fêtes de Saints Pierre et Paul et de Sainte Petka}

\section{- La fête de Saints Pierre et Paul}

Ce kurban est réalisé le 29 juin, jour de Saint Pierre. Depuis 1979, une personne est responsable de cette célébration. Quand elle accepta la responsabilité de préparer la fête pour Saints Pierre et Paul, le kurban n'était plus organisé. D'après ses informations, un kurban était célébré, il y a longtemps. Sa décision de devenir responsable a été prise par hasard mais néanmoins décidée avec d'autres personnes. Voici ce qu'elle raconte : " nous étions trois amis en 1978 et dans un bar de la ville, nous avons rencontré un pope et je lui ai demandé pourquoi cette chapelle est délaissée et ce qu'il faut faire. Il a dit : "je ne sais pas qui était responsable avant mais on faisait un kurban" et alors le docteur G. m'a donné 10 leva en me disant : "tu deviens le caissier du kurban" „36. Après cet engagement, cet homme prit la décision de construire une nouvelle chapelle consacrée aux deux saints Pierre et Paul, l'ancienne chapelle étant délabrée. Cette personne gère l'ensemble des préparatifs mais est aidée d'un groupe de villageois qui vivent dans le même quartier qu'elle. Une centaine de personnes assistent à ce kurban qui est réputé sur l'ensemble de la commune et de ses environs. La chapelle se trouve à une dizaine de kilomètres du centre du village, dans la montagne.

Dans le cas de cette fête, il nous est possible de mettre en évidence un premier type de démarche. Une personne accepte la responsabilité de préparer une fête. Aidée des villageois de son quartier, elle organise et gère l'ensemble des tâches. L'objectif de cette célébration est de perpétuer une tradition. En effet, le respect de ce rituel en l'honneur d'un saint est la raison évoquée par le responsable pour expliquer l'origine de cette célébration : " un respect envers le saint et c'est pour cela qu'on le fait. Ici, c'est une tradition car nous avons beaucoup de chapelles et pour chacune, on fait un kurban "37. Son choix a été principalement motivé par des amis ou des personnes disposant d'une certaine autorité (un médecin et un pope). La décision de s'engager dans la réalisation d'un kurban n'est pas le résultat d'un cheminement personnel mais

35 Entretien, octobre 1999.

${ }^{36}$ Entretien, mai 2000.

37 Entretien, novembre 2000. 
d'une volonté extérieure. Il se sent investi d'une responsabilité collective : " quand une chose est commencée, il faut l'entretenir jusqu'à la fin " $^{8}$. Il est responsable du kurban et participe du mieux qu'il peut à l'ensemble des préparatifs pour satisfaire les villageois présents.

\section{- la fête de la Sainte Petka}

Le kurban de Sainte Petka est célébré depuis de nombreuses années ; aucun organisateur n'a pu dire concrètement depuis quand. La chapelle se situe dans le deuxième quartier où sont réalisés trois autres kurbans. Jusqu'en 1998, le responsable des autres célébrations gérait également cette fête. À l'époque, à l'emplacement de la chapelle se trouvait une croix votive. Pour le 14 octobre, jour de Sainte Petka, ce groupe d'organisateurs préparait un kurban modeste. Deux à trois bêtes suffisaient car peu de monde s'y rendait. Or en 1998, un groupe de villageois, membre d'un comité de protection du patrimoine, prit la décision de construire une chapelle au lieu même de cette croix. Lorsque la chapelle fut terminée, le 14 octobre 1998, le précédent organisateur, bien qu'il eut la possibilité de continuer, se déchargea de cette responsabilité ; certains des membres du comité d'initiative reprirent la préparation du kurban. Or, pour ces nouveaux responsables, la réalisation de cette fête est uniquement possible grâce à l'aide d'autres personnes, elles-mêmes, organisatrices de kurbans : " nous sommes trois pour le kurban mais pour la cuisine, il y a des gens qui viennent aider car seuls, on ne peut pas faire toute la préparation "39. Pour ces nouveaux organisateurs, la préparation de ce kurban n'est pas une fin en soi : " on voulait faire un endroit où les gens puissent allumer un cierge. Avant il n'y avait pas de toit et de quoi se protéger. La question n'est pas d'être responsable du kurban. (...) Je n'avais ni la volonté de faire un kurban ni le désir d'être responsable. Mais j'ai promis de faire cette chapelle "40. Les responsables de Sainte Petka se considèrent avant tout comme les responsables de la chapelle. Ils ont accepté malgré tout la responsabilité d'organiser le kurban pour rendre honneur à la sainte. L'important est plutôt, selon ces organisateurs, de permettre à chacun des villageois de pouvoir se recueillir dans un lieu bénit et consacré.

Chaque personne du groupe a une tâche bien définie : la vente des cierges, l'accueil des villageois, la préparation du kurban, la récolte de l'argent déposé dans l'église. Les aides, organisateurs d'autres kurbans du troisième mahala et reconnus pour la qualité de leur travail, sont présents uniquement pour la logistique du repas. Les responsables, eux, gèrent l'accueil. Chaque villageois qui

39 Entretien, avril 2000.

$4^{\circ}$ Entretiens, avril et juin 2000. 
arrive est alors reçu par l'un des membres vêtus pour l'occasion de ses habits du dimanche. Ils tiennent à se démarquer des autres groupes mais surtout à accueillir correctement les invités de la Sainte. Par exemple, en 2001, chaque personne participant de près ou de loin à l'organisation de la fête portait sur sa tête une même casquette et un tablier identifiable.

Dans ce deuxième type de démarche, les nouveaux responsables sont avant tout présents à la fête pour superviser l'ensemble de l'organisation. En effet, le choix d'organiser ce kurban n'est pas dû à une proposition soumise par une tierce personne. Leur choix est la conséquence d'un acte préalablement réfléchi, celui de construire une chapelle. La décision de s'engager ensuite dans la réalisation du kurban a été prise par respect envers la Sainte. Ils se sentent alors responsables personnellement.

Lors des entretiens effectués auprès des principaux organisateurs, les raisons évoquées pour justifier la réalisation de ces festivités étaient motivées par la nécessité de maintenir et de respecter une "lointaine" tradition. Or, depuis 1998, les changements intervenus au sein de l'organisation des kurbans ont permis à certaines personnes de participer et de s'impliquer dans l'élaboration de ces célébrations. La présentation des deux kurbans a permis de distinguer deux démarches différentes quant aux raisons de devenir responsable. Le premier type, celui de la fête de Sts Pierre et Paul, correspond à la démarche la plus souvent présentée par les organisateurs et considérée par ces personnes comme la plus régulièrement pratiquée : " j'ai décidé quand les vieux se sont rassemblé et m'ont demandé que cela soit le plus jeune qui soit responsable et exécute cela. Ce sont eux, les plus âgés, qui m'ont proposé car "nous n'avons plus de force pour cela" " $4^{41}$. Le choix de devenir responsable n'est pas dû principalement à une motivation personnelle mais dépend avant tout de la décision de l'ensemble du conseil ou d'un groupe de personnes. Il y a alors cooptation. Pour le deuxième cas, celui de Ste Petka, les organisateurs ont fait un choix personnel lié à l'envie de réaliser une nouvelle chapelle, une nouvelle fête. Ils se considèrent comme responsables de la chapelle et par conséquent du bon déroulement de la fête organisée en l'honneur du saint patron. La décision qui consiste à prendre en charge la préparation du kurban dépend donc d'un choix personnel et non d'une décision émanant de tierces personnes. Or, la participation et l'implication de ces nouveaux venus ont transformé peu à peu certains aspects de l'organisation de ces fêtes. Ces changements récents et la venue de ces nouveaux organisateurs ont-ils également modifié certains rapports entre les organisateurs ? 


\section{Kurbans et reconnaissance sociale}

La fête est définie, par l'ensemble des responsables, comme un moment de rencontres et d'échanges autour du repas : " c'est surtout une réunion et la réunion consolide les rapports entre les personnes. (...) C'est important parce que lorsqu'on y va, on voit des gens que l'on n'a pas vu durant l'année " $4^{2}$. Une des fonctions premières de la festivité est de réaffirmer les liens qui unissent le groupe. Cet acte collectif suppose non seulement la présence d'un groupe mais également sa participation; lors de ces rencontres festives, les villageois peuvent alors se retrouver pour partager des moments de convivialité : " c'est agréable pour moi, pour voir des amis, on mange et on boit un verre. On échange des pensées non seulement concernant la religion mais aussi la vie quotidienne "43. Mais si la fête est un lieu de la communication, d'échange et de cohésion sociale, elle permet également de mettre en évidence certains rapports de pouvoir existants entre les différents groupes d'organisateurs. En effet, le responsable du kurban, qui participe au maintien de cette tradition, acquiert une certaine notoriété au sein du village. Et parce qu'il y a reconnaissance sociale, les rapports de pouvoirs entre les organisateurs ont évolué pour s'adapter à la nouvelle situation.

Les nouveaux responsables sont conscients qu'ils contribuent au maintien de ces fêtes de façon différente, par l'apport de nouveautés au sein du village : la création d'un nouveau kurban ou la protection du patrimoine religieux : " notre kurban [celui de Ste Petka] n'a rien de commun avec les autres kurbans. Pourquoi ? Parce que nous avons commencé les derniers à faire les choses comme cela et moi j'ai pris l'initiative de tout le travail et de construire cette chapelle. (...) Cela dépend de la morale et de la volonté de chaque individu " 44 . En mai 2001, à l'occasion de la fête de St Georges, certains membres du comité de protection du patrimoine, également organisateurs 45 , se sont engagés à restaurer la chapelle. Les travaux devaient être terminés pour le 6 mai lors de la fête. Leurs objectifs étaient de donner à ce kurban un nouvel attrait : " tout doit être prêt pour le 6 mai, pour la fête et je suppose que cela sera mieux que ce qui a eu lieu jusqu'à maintenant $"{ }^{46}$. En effet, au cours des deux dernières années, les responsables de l'organisation de cette fête, non cooptés, n'avaient pas été scrupuleux : " ce n'est pas la personne convenable même si durant un an, il a été responsable. Il n'a pas sa place pour ce travail "47. La participation de ces

\footnotetext{
$4^{2}$ Entretien, avril 2000.

43 Ibid.

44 Ibid.

45 Ces personnes font la distinction entre leur engagement à l'égard du comité de protection du patrimoine et leur implication dans l'activité festive. Elles sont responsables d'une fête mais prêtent avant tout attention au patrimoine religieux du village.
}

46 Entretien, avril 2001.

47 Entretien, mai 2000. 
nouveaux organisateurs à l'organisation des fêtes est motivée avant tout par leur intérêt pour la protection du patrimoine et pour la tradition. Mais, se trouvant impliqués dans l'organisation de ces festivités, ils cherchent à se distinguer de certains responsables qui réalisent la fête dans un but plus "commercial” : " je n'ai pas de relations avec les autres kurbans parce que les autres sont pour moi des kurbans commerciaux. Je veux faire un kurban uniquement dans un but non lucratif. (...) Pour moi tant que je suis vivant, cela ne se passera pas comme chez eux ${ }^{48}$, " Il y a un but commercial mais parfois on s'éloigne du but qui est d'honorer le saint pour en faire un profit commercial. (...) Ce n'est pas le profit qui est important même si on dépense plus. Ce n'est pas bien car les gens sont allés pour s'asseoir, se distraire et eux [les responsables d'un autre kurban] voulaient imposer une nouvelle mode sur un terrain où il y a une tradition déjà établie "49. Effectivement, certains responsables ont pour pratique de réserver une quantité plus importante de kurban pour la vente et non pour la distribution sur place. Comme il est possible de ramener chez soi un peu de soupe bénite, cette vente permet de s'assurer un bénéfice plus sûr. La part de soupe est payante et la somme fixée est ensuite variable selon la quantité demandée par le villageois. Or, la distribution de kurban durant la fête rend au contraire les gains plus aléatoires ; les dons offerts dépendent des villageois et non du responsable.

Leur contribution se démarque également par la volonté de proposer aux personnes se rendant à la fête un lieu agréable : " on voulait faire un endroit où les gens puissent allumer un cierge. Avant il n'y avait pas de toit et de quoi se protéger " 50 car la plupart des lieux où se déroulent les kurbans sont très peu aménagés.

Depuis leur engagement, ces nouveaux organisateurs sont peu à peu reconnus et respectés par les autres responsables : " pour Ste Petka, c'est le comité de l'organisation qui est beaucoup plus fort et avec des gens très entreprenants $n^{51}$. Ils sont également considérés par l'ensemble des villageois comme des personnes de confiance : " cela est très beau, depuis longtemps, il fallait la construire [la chapelle Ste Petka]. (...) C'est une très belle chose car c'était comme pour St Trinité, une croix en pierre ${ }^{52}$. Leur implication s'est matérialisée par la construction et la restauration de chapelles, par le respect de leur engagement et par une présence active lors des fêtes qu'ils organisent. Cette reconnaissance a été progressivement acquise après avoir démontré qu'ils

\footnotetext{
$4^{8}$ Ibid.

49 Entretien, novembre 2000.

50 Entretien, avril 2000.

${ }^{51}$ Entretien, décembre 1999.

$\varsigma^{2}$ Entretien, mai 2000.
} 
étaient capables de respecter leur parole et leur promesse. Mais l'implication de ces nouveaux responsables ne se limite plus à la simple restauration de chapelles ou à la nouveauté, certains s'engagent personnellement à choisir de nouveaux responsables. Dans le cas de la fête de St Georges, les membres du comité de protection du patrimoine ont choisi la responsable du kurban, l'ancien responsable n'étant pas considéré par l'ensemble des organisateurs. Cette nouvelle recrue accepta la proposition : " ce sont les personnes les plus importantes. Je les ai rencontrées sur la grande place à côté de la mairie et elles m'ont dit qu'elles m'avaient élue comme caissière-comptable : "nous avons confiance en toi et tu feras l'affaire. Tu as de l'autorité parmi les gens" "53. Or, depuis l'implication de ces nouveaux organisateurs, s'instaure progressivement une certaine forme de lutte de pouvoir symbolique entre certains responsables : " j'ai moins de liens et ils sont plus forts. Ils savent marchander "54, "À Ste Petka, tout est très bien fait, on peut allumer un cierge. Ils ont un abri, ils sont plus riches, ils sont plus insistants "55. En effet, étant reconnues comme des personnes de confiance et concrétisant leurs projets, leur participation à l'organisation des festivités génère alors une sorte de surenchère, celui qui fera plus, celui qui proposera mieux : " ce sont des personnes nouvelles. Moi aussi, j'ai des idées pour faire quelque chose, il faut parler avec des gens [peintres et restaurateurs] pour qu'ils viennent $" 5^{5}$. À chaque fête, le responsable met alors sa réputation et sa notoriété en jeu.

\section{FÊTES TRADITIONNELLES ET NOUVEAUX ORGANISATEURS}

Pendant plus de quarante ans, les festivités ont été utilisées à des fins politiques et de propagande. Si l'essence religieuse avait été niée, la structure traditionnelle et historique de la fête avait été préservée pour servir la cause nationale. Toute l'activité festive était gérée par les maisons de culture dont le rôle était de proposer des soirées durant lesquelles coutumes et rites étaient présentés au public. Actuellement, le rôle des čitalištes est moindre et ne permet plus comme par le passé le partage et l'échange au travers de référents culturels et identitaires. D'où l'intérêt croissant pour des festivités d'un type plus traditionnel-les kurbans - qui permettent à un ensemble de villageois de pouvoir se retrouver afin de partager des moments de convivialité. Cet intérêt ac-

\footnotetext{
53 Ibid.

54 Entretien, novembre 1999.

55 Entretien, avril 2001.

${ }^{56}$ Entretien, mai 2000.
} 
tuel pour la tradition et pour la religion, qui se manifeste entre autre par la construction ou la restauration de chapelles, est exploité le plus souvent à des fins identitaires. Parallèlement, l'implication récente de certains villageois a remis en question les rapports existant entre les différents organisateurs. Ces nouveaux responsables, considérés et reconnus depuis leur engagement, par la plupart des autres organisateurs, affirment leur autorité et deviennent alors les référents au sein de l'organisation des festivités. La présence de ces nouvelles personnalités génère une forme de surenchère où chaque responsable d'une fête se doit de faire mieux que l'autre. Au-delà de son intérêt religieux, le kurban s'impose comme un lieu de sociabilité mais également comme le lieu de reconnaissance sociale synonyme d'une forme de lutte de pouvoir symbolique. 